\title{
Eurocentrismo y perspectivas epistémicas ${ }^{1}$
}

\author{
Aníbal Quijano
}

Probablemente yo no hice algo muy atinado cuando dije que este patrón está en crisis porque, claro, eso abre muchos cuestionamientos. Lo que quiero examinar es el modo de producir conocimiento. El eurocentrismo es un modo de producir y de controlar subjetividad. Esto implica imaginario, memoria social, conocimiento, entre sus elementos fundamentales. Los debates sobre el eurocentrismo tienen ya una larga data. También, hay algo que ha ido desarrollándose, sobre todo desde la segunda guerra mundial, que es una suerte de callejón de los "post»: posthumanismo, post-estructuralismo, post-marxismo, post-colonialismo. Afuera, seguramente, esta literatura llamada post-colonial, en la cual en muchos lugares también nos incluyen a muchos de nosotros. ¿Cuándo comenzó lo poscolonial? Me gustaría proponer a ustedes la idea de regresar a América Latina, que ocupa un lugar, como hemos visto, fundacional en la emergencia de este patrón de poder que podemos reconocer como colonial.

La colonialidad del poder emerge aquí como América y, por lo tanto, ocupa una posición fundacional. Es el momento del tiempo inaugural y el espacio original de este patrón de poder. Eso seguramente explica por qué no solamente el debate comienza temprano en América Latina, sino que por América Latina finalmente comienza el debate en la futura Europa occidental. Y comienza en el mundo

\footnotetext{
1 Este texto es la transcripción de la conferencia de Aníbal Quijano en el marco de la tercera sesión del taller titulado "Colonialidad del poder», organizado por el Grupo de Investigación sobre Conflictos y Desigualdades (GICO), coordinado por Narda Henríquez, con el auspicio de la Maestría en Sociología y el Departamento de Ciencias Sociales de la Pontificia Universidad Católica del Perú (PUCP). Este texto fue transcrito por Adolfo Palacios, editado por Julio Villa-Palomino, y revisado por Guillermo Rochabrún. El equipo editorial de Debates en Sociología agradece la dedicación y diligencia del equipo mencionado
} 
ibérico con la famosa reunión de Valladolid. Si ustedes releen Nueva Crónica y Buen Gobierno (1615), no hay explícitamente cuestiones, pero hay algo ahí implicado. Para los historiadores del siglo XX, en el Perú, por ejemplo, este era un texto marginal. Mucho después ha reingresado como un texto central para el debate peruano.

Pero aún en el propio Garcilaso, no obstante las distancias, ustedes encuentran la constante apelación a la indianidad. O sea, admitida ya la denominación colonial «indio", hay una suerte de indianidad que él admite y de la cual puede incluso enorgullecerse. ¿Qué implica eso? Él ha pasado todo su desarrollo intelectual en términos de lo que proviene de Iberia. Pero el imaginario al cual él apela todo el tiempo, la memoria a la cual él apela todo el tiempo no es esa: es otra. Él dice «me contaba así» tal pariente... Como ocurre en la literatura peruana de provincia, la mayor parte de narradores provienen de la fauna social que tiene servidumbre doméstica, ¿no? Como han vivido con ellos mucho tiempo han escuchado sus historias. Y, muchos de ellos dicen "esto nos contaba...». Entonces, el imaginario de la fauna gamonal del país estaba hecho no solamente de la memoria de su propia fauna sino de mucho más. Algo que producía una suerte de alquimia que Arguedas procura exactamente hacer.

Probablemente el primer caso mayor de esa realización lo tuvo Guamán Poma de Ayala, la crónica india. La historia maya no es en ese momento vigente y los textos se traen mucho más tarde. Pero hay efectivamente una suerte de resistencia que no se detiene, que va formulándose constantemente. La resistencia contra el eurocentrismo se da de manera inevitable puesto que este era el espacio inicial, el tiempo inaugural de ese patrón de poder. El conflicto, por lo tanto, está ahí incorporado desde el momento mismo de la formación que está en y con América Latina.

Entonces, cuando uno piensa en este debate llamado poscolonial, es algo muy presente. La posición, a mi juicio, es equivalente a la de los latinoamericanos desde fines del siglo XIX en adelante. De Martí, sobre todo, en adelante. Y, sobre todo en el siglo XX, de Vasconcelos, de Haya, Mariátegui, que van en la misma dirección; reclaman lo mismo: «Ustedes son europeos, no conocen nuestra historia. Nosotros sí podemos hablar desde adentro», que es la línea de lo poscolonial. «Ustedes no conocen nuestra historia, nosotros sí». No importa que aún se nombre la palabra «Indoamérica», que dicen que fue acuñada por Vasconcelos, adoptada por Haya. Socialismo indoamericano después, por Mariátegui. Pero con la excepción de Mariátegui —y no estoy seguro cuán consciente era él de lo que estaba haciendo en ese momento-, para todos los demás, los presupuestos, el piso epistémico es el mismo. Por lo tanto, los dos movimientos son teóricos, históricos, políticos. Son también parte de este largo callejón autocrítico que comienza a revelarse sobre todo desde Europa, en esto que se está llamando el callejón de lo post. Pero, yo no diría que hay una subversión epistémica. 
Dentro del debate de la colonialidad del poder, lo que está emergiendo es lo que pienso que es legítimo presentar como una perspectiva epistémica. Es una perspectiva epistémica, teórica, histórica, estética, ética, política. Algunos años atrás, en un debate en Cartagena, en Colombia, gente de varios países de América Latina y de varios otros lugares había sido convocada para discutir lo que pasaba con la izquierda en ese momento en América Latina, y yo dije lo que aquí estoy diciendo. Mi propuesta fue que el eje de las dificultades es que se trata de una ideología de izquierda montada sobre una epistemología de derecha. De algún modo, la publicación de eso llegó a Francisco Miró Quesada, el filósofo. Y él publicó un artículo en el periódico; una reflexión en torno a eso. Esta novísima pregunta histórica: «¿Qué son?, ¿son humanos, o no son humanos?». Esto hace parte del horizonte de sentido cuyo piso epistémico último ha sido producido desde una propuesta místico-metafísica que está activa y que sigue estando activa.

Por eso, yo quisiera aquí convocar a ustedes al debate de uno de los productos de esa episteme: un dualismo radical cuyo elaborador más reconocido, que permite la generación de este piso epistémico formalizado, propuesto como una episteme formalmente elaborada — por lo tanto, como una filosofía—, es René Descartes. En términos formales, teóricos, filosóficos, esto es un fenómeno nuevo de más o menos cerca de la mitad del siglo XVII. Pero no es nuevo en el modo de pensar y mirar el mundo. Es nuevo como formalización, como elaboración teórica y filosófica pero no es nuevo como un modo de producir sentido y de explicar el mundo. Por lo tanto, en la pregunta "¿son humanos, tienen alma?», el piso, el más profundo nivel de donde proviene la mirada ya está ahí implicado. No es un fenómeno que parece reconocible en la gran mayoría de otras culturas: China, India, Egipto, Mesopotamia, en lo que se va cocinando en el mundo de las religiones producidas en medio oriente, y en el mundo maya, azteca, andino, allí no aparece, no en todo caso con las mismas características.

Más o menos, se va generando el mismo horizonte histórico. Hay algo allí que se produce. Cómo y por qué es más difícil. Hay muchas explicaciones. Una que circuló mucho es la de la separación de alma y cuerpo. Como todos saben, el alma es inmortal, el cuerpo no. El cuerpo es mortal y perecedero. Entonces, hay una muy larga teología cristiana que atraviesa toda la Edad Media y que, por supuesto, es defendida y alimentada por el cristianismo de la contrarreforma. Hay una división ética entre alma y cuerpo. Entonces, ya se ha producido esta división originaria, con el piso más profundo de la mirada sobre el mundo. Hay dos cosas aparte: lo que pertenece a aquello que es inmortal, y ¿por qué es inmortal? Porque tiene carácter divino, mientras que lo otro no. Es creado por Dios, pero con otro carácter. Razón, sujeto de objeto. 
¿Por qué estoy hablando de separación? Solo tienen que volver a mirar a Descartes. La razón es divina. Es un don que Dios ha dado a sus criaturas. Estas criaturas están hechas a imagen y semejanza de Dios. Esa imagen y semejanza, además, es lo que permite ser seres racionales dotados de razón. La razón tiene carácter divino y en consecuencia es diferente de todo lo otro. Entonces, propongo que aquí tenemos un fenómeno nuevo en la manera de conocer y de mirar el mundo. Toda relación social, toda práctica social tiene dos dimensiones. Una que se ve, que se puede palpar; incluso puede tocarse; hay una materialidad en toda relación social. Pero hay algo que además no es tangible ni visible, y que llamamos — también, heredamos todo eso- subjetividad.

En todas las áreas de diversas formas de existencia social, todos los individuos, sin duda, han aprendido a distinguir lo que uno sueña, imagina, piensa, anhela. Pero además hace, o deja de hacer: tenemos gestos, ademanes, actos, movimientos. Son dos áreas indudablemente diferentes. Entonces, la diferenciación está clara. Tras la derrota de los moros y la expulsión de moros y judíos, ninguno de ellos defendía lo mismo: en los moros y los judíos de la Península, esta separación entre alma y cuerpo, esas cosas, no tiene la misma densidad que después del debate Reforma-Contrarreforma.

Alma y cuerpo es un dualismo radical en un sentido muy específico. La última referencia previa de la diferenciación entre estas dos dimensiones de la existencia social sería el Fedón de Platón. Hay una diferencia muy clara entre estas dos dimensiones. Pero es por primera vez que, en términos filosóficos, intelectuales, teóricos, no solamente aparecen diferenciados sino separados. No son lo mismo, no tienen que ver. El cuerpo es el continente de la razón. Y, por eso, si ustedes leen la literatura filosófica europea, en el debate de la modernidad el cuerpo para muchos aparecía como una cárcel del espíritu, que no lo dejaba volar libremente. El dualismo radical es por eso una novedad. Es un producto de esto que estamos llamando la colonialidad del poder.

La propuesta cartesiana hace de la razón un don divino; todo lo demás es también creación divina pero no tiene categoría de divino. Somos seres racionales porque tenemos razón, y la razón es un don divino. Esto está literalmente dicho, escrito. Por lo tanto, emerge una figura nueva: el cuerpo. Antes era alma y cuerpo; ahora es razón y cuerpo. La razón no es exactamente el alma en el mundo religioso. Incluso hay debates entre la racionalidad científica, la doctrina y las creencias. Parten de lo mismo, pero se diferencian mucho. Esto es algo que tiene origen místico, pero que termina siendo admitido como el fundamento mismo de la racionalidad moderna. Sin eso no sería posible la ciencia. Por lo tanto, el que conoce, es alguien que usa la razón, ese don divino. Y eso está adentro. Es, en consecuencia, un sujeto. Y lo que se conoce está afuera, es un objeto. Sujeto es lo que está dentro; por lo tanto, es lo 
que usa la razón. Sujeto, por lo tanto, es el que conoce y todo lo que es conocido; lo que va a ser conocido, puede ser conocido, está afuera. Esa es la razón, y todo lo demás es naturaleza. La idea de naturaleza viene de más atrás. De Bacon para adelante. Pero es aquí donde obtiene su lugar formal. Entonces, este dualismo radical, ¿qué carácter tiene?

Cuando en el siglo XIX Europa va colonizando el resto del mundo aparecen además dos disciplinas interesantes en Europa. A fines del siglo XIX ya teníamos la palabra: es híbrida del griego y el latín, como todo el mundo sabe: sociología. Eso es estudiar la sociedad. Y lo que estudia los otros pueblos, a los africanos, los chinos, ¿es la sociología? No. Se llamaba etnografía. Entonces, la antropología puede hacer lo que se llama etnografía: eso es lo que se estudia. El que estudia es el racional. ¿Y quién es el racional? Es el sujeto cognoscente; es, por lo tanto, por definición, el moderno, el racional. ¿YY, quién es racional y moderno? El europeo. ¿Qué es eso? Los demás pueblos son «indígenas». Se da ahí un sur global. Hay una indigeneidad global que comienza aquí. El primer segmento de la población del mundo en ser indigenizado es América.

Este es un asunto extremamente importante porque hay que salir de él. ¿¿Por qué hay que salir de allí? Estarán de acuerdo en que el dualismo radical produce obstáculos y dificultades no salvables para un apropiado re-conocimiento del mundo y en particular de la historia, de la existencia social. Para toda una vasta población, la separación entre razón y naturaleza permite obviamente hacer lo que antes para ellos no era posible. Permite experimentar, ya no solamente con lo que no es parte de la especie, sino con lo que forma parte de la propia especie. Comenzando con una parte de la naturaleza que somos nosotros, que es el cuerpo. Puesto que la razón es divina y el cuerpo no, el cuerpo es naturaleza. Por lo tanto, se puede experimentar con el cuerpo. Entonces, se puede hacer ciencia en ese sentido.

La ciencia — por eso la insistencia de ahí para adelante— tiene que ser objetiva. Para ser legítimo y validado, todo conocimiento tiene que ser objetivo. Es decir, el sujeto que conoce es el portador de la razón, que es un don divino. Todo lo demás está fuera de él. Por lo tanto, es juez de todo. Y para comenzar, se puede experimentar con él. El sujeto cognoscente es ahí, por definición, europeo. En el siglo XVIII ya se dirá blanco, desde Estados Unidos. Será europeo y blanco el sujeto cognoscente.

¿Qué es lo que está implicado en este dualismo radical cartesiano? No solamente está la secularización de esta prolongada teología cristiana medieval. Está también el propio patrón de poder colonial moderno. Es el racismo que está implicado en este patrón. Por eso cuando ellos se van a colonizar el resto del mundo, esta forma de conocer, este dualismo radical, pasa a ser consolidado, legitimado, desarrollado, absorbido por ellos y por los demás. Por los que ellos colonizan y persuaden a 
abandonar sus viejas maneras de conocer. Incluso bajo la represión. El racismo ya está implicado acá, y se consolida en el proceso de expansión del dominio colonial de la nueva Europa sobre el resto del mundo.

Hay pues una episteme racista, y su punto de partida formal, su formalización como el piso de la racionalidad llamada moderna y colonial, es esta. No se puede subvertir este orden sin subvertir, además, los supuestos, los fundamentos de su horizonte histórico de sentido, de su modo de conocer, del modo en el que se produce y se controla la subjetividad. Porque eso permite decir «ustedes son primitivos, nosotros modernos». Por eso aquí tenemos un nudo realmente demasiado importante que tiene que ser ubicado y desatado. Porque la experiencia de América es la primera que muestra exactamente que así no es. Toni Negri es quien ha seńalado que no se puede re-conocer la existencia social de la especie, su historia y su trayectoria, sin salir de este dualismo radical. Porque la pretensión de un conocimiento del sujeto con razón divina hacia afuera produce el olvido de que todo proceso de conocimiento implica ya una intervención.

Probablemente para nosotros lo más trivial que permite entender la propuesta diferente es la idea local de Pachamama. ¿Qué es Pachamama? Hay un discurso curioso en este momento. Si ustedes leen las publicaciones de muchos grupos indigenistas, o indígenas, una de sus propuestas es la vida en armonía con la naturaleza. Lo que implica que ellos siguen siendo tributarios de esta división entre la razón y la naturaleza. Nosotros los humanos debemos vivir en armonía con la naturaleza. O sea, nosotros, por lo tanto, no somos parte de la naturaleza. Pero la idea de Pachamama es, exactamente, algo muy profundamente distinto. Todos pertenecemos a este mundo de maneras muy diferentes, pero estamos en relación. No hay un don divino que nos separa de los demás. Entiendo la duda de cómo repensar todo esto e ir hacia la producción de otra episteme.

Esto nos permite, entonces, pensar una segunda cuestión. La cuestión de la totalidad. Si se admite el dualismo radical cartesiano como el piso mismo del modo de conocer, la idea de totalidad es inútil, no tiene legitimidad, no tiene pertinencia. Ustedes deben haber visto un libro que fue muy célebre el siglo pasado, de un filósofo español muy importante; además porque tiene un título precioso. Se llama Naturaleza, historia, dios, de Xavier Zubiri. Deben haberlo visto. Además, es muy inteligente y muy ingeniosa la propuesta. Porque estos tres ámbitos son fundamentales en la existencia universal: naturaleza, historia, dios. Y en la historia juega, por supuesto, la razón. Entonces, es inútil. No solamente es inútil, es impertinente. No puede ser un instrumento del conocimiento. La idea de totalidad, por lo tanto, queda descartada. En el caso del debate europeo por la centralidad de Europa en el control de este patrón de poder, uno de sus instrumentos centrales no es solamente el capital y el capitalismo, sino esta razón, esta racionalidad, este horizonte de sentido 
que llega a ser impuesto mundialmente. Si no admitido por todos siempre, incluso formalmente admitido hasta posiblemente alrededor de la segunda guerra mundial.

La resistencia es temprana, pero no hay una formalización de esa resistencia porque esta no es posible. Sería reprimida, sería penada, sería castigada. Sería una revuelta. No se puede pensar sin subvertir el orden en el que se sostiene esta forma de conocer y de pensar. Es reprimida, y la represión se da en muchas formas. Desde el silencio hasta la violencia. Por eso, que Europa produzca el eurocentrismo y lo convierta en un eje del dominio mundial del horizonte de sentido no es por lo tanto incomprensible. Lo que sí es realmente notable es cómo llega a ser mundialmente admitido. Sin el carácter colonial del dominio europeo, e incluso después de la «independencia», se sigue el mantenimiento de todo el patrón de poder impuesto bajo la colonización. El poder sigue teniendo carácter colonial. La colonialidad del poder existente ayuda a entender por qué todos los que habitan, emergen, se educan, estudian, conocen, lo hacen desde dentro de este patrón de poder. Incluso cuando están en contra.

Hay un lugar central, fundacional, de América Latina en la construcción de este patrón de poder. En el horizonte de sentido colonial moderno América Latina no tiene un papel tan central. La centralidad es Europa. En el horizonte histórico de dar sentido al conocimiento, la centralidad es la nueva Europa, pero la presencia de América Latina está ahí. Y por eso es en América Latina donde comienza primero la resistencia, pero también por esto es por lo que la ruptura comienza a producirse curiosamente también aquí.

La destrucción de América fue, realmente, de proporciones históricas muy grandes. No solo en términos demográficos, de mortandad, sino de destrucción de todo un mundo histórico, milenario. Esto no ocurre en China, no ocurre en la India. Ocurre casi algo parecido en África, pero no de esa magnitud, no de esa densidad; no es todo el mundo histórico que está en escombros. Por lo tanto, probablemente, la resistencia ahí tuvo el mismo vigor, pero no tenemos la posibilidad de leerlo, de informarnos de él, de discutirlo. Como sí desde América Latina, y más tarde desde Europa después de la segunda guerra mundial.

Uno puede pensar que la revuelta comenzó bastante antes. La producción de eso llamado marxismo, de los manifiestos, del Manifiesto Comunista. Parece haber una revuelta, pero no hay una revuelta a ese nivel. Hay una revuelta teórica, política; no hay una revuelta epistémica. Lo que está implicado como posibilidad de ruptura epistémica no llega a materializarse. Marx llega a ser consciente del eurocentrismo poco antes de morir. En el debate y la correspondencia con los llamados después «populistas rusos» es claro que él va a tener conciencia de eso, pero no tiene la posibilidad de resolver el asunto. Sí pone en duda algunos fundamentos de su propuesta. Su primer biógrafo, Riazanov, señala que Marx estaba dejando de ser marxista en ese momento y que estaba entrando en la senilidad. Hay una senilidad 
mental en Marx. Tenía 63 años en ese momento. Así que ya ustedes ven cómo es costoso desprenderse de estas prisiones eurocéntricas.

La idea de totalidad, por lo tanto, para quienes admiten este piso epistémico no es posible, no es pertinente. Cuando se pone en duda eso es cuando aparece una revuelta antimística, desde el siglo XVIII sobre todo, en Europa central. En la Europa nórdica la experiencia de revuelta es muy temprana y termina en un compromiso. La aristocracia sigue siendo la misma, pero se aburguesa. La otra resiste, tiene que ser echada. La revolución tiene que botarlos de su lugar, cambiarlos de su lugar. Entonces, el poder no se puede comprometer. Tiene que ser destruido. Y eso permite, en consecuencia, otro contexto para el debate intelectual. Por esto la revuelta antimística produce sus primeros intentos de ruptura epistémica, y por eso se admite desde fin del siglo XVIII, comienzos del XIX, pero no llega del todo. ¿Por qué?

En el debate entre Alemania y Francia hay un modelo que ha invadido la idea científica de naturaleza. El cuerpo es naturaleza. Por eso, muy temprano ya tenemos al mismo tiempo biología y botánica. La biología está produciendo un conjunto de modos de pensar categorías que naturalmente entran en el debate de las gentes que se ocupan de la sociedad. Por eso las palabras «estructura» y "proceso». Pero luego la palabra «órgano», la palabra "organismo». Sin la idea de organismo, ver la totalidad no es necesario. Pero con la idea de organismo, la idea de totalidad es inevitable. Entonces, toda la parte "progresista", más adelante revolucionaria, del debate entre Alemania y Francia, propone la idea de totalidad respecto de la existencia social, de la historia, de la especie, la de organismo. No solo los individuos tenemos organismos: la sociedad es un organismo y funciona como tal. Hay una idea de totalidad, pero esta totalidad es como un organismo.

No mucho después viene una propuesta diferente: la de la idea absoluta, que se va llevando a cabo en el curso de la historia de la especie. La historia es, en ese sentido, una realización de la idea absoluta. Hay ahí una idea de totalidad, pero no es histórica; es una totalidad místico-metafísica. Toda la historia de la especie, la historia de la humanidad, se explica como realización de la idea absoluta, una totalidad metafísica. Esas dos ideas de totalidad van a ser competitivas en el debate eurocéntrico, que se hace mundial. Y la idea de organismo atraviesa todo el debate teórico-político de ahí en adelante hasta hoy. Toda la llamable «izquierda» no puede pensar a la historia sino con la categoría de totalidad como realización de ideas absolutas.

Antes no se cuestiona el poder: no hay poder; lo que hay es un orden social natural producido por consenso y tiene autoridad natural. Pero la cuestión del poder, la necesidad de hacer saltar el poder, de subvertir el poder, la lucha por el poder y contra el poder, requiere la idea de totalidad. Pero esa totalidad es organicista, y nos atraviesa a todos. ¿Por qué organicista? Porque también es una vieja herencia que viene desde el mundo románico. Porque todo organismo tiene un ente, un eje 
rector, que articula, organiza, totaliza y dirige, controla. El organismo es el cerebro. En la sociedad también. ¿Qué es eso?: el poder, sobre todo político.

Por ejemplo, en la social democracia, o con Lenin, hay una división casi natural. ¿Quién es el cerebro, entre los intelectuales y los obreros? El cerebro son los intelectuales. Los obreros por su propia cuenta no pueden llegar a tener conciencia de clase. Tiene que ser llevada desde afuera por la inteligencia de las capas medias de la burguesía. En el debate en América Latina, la idea es que el partido es el cerebro y los sindicatos son las extremidades. El organismo, por lo tanto, pasa a ser la imagen necesaria de totalidad para la lucha con — dentro de- el poder. En el liberalismo no existe la idea de totalidad hasta la segunda guerra mundial: el estructural funcionalismo admite la idea de totalidad, pero como sistema; la idea de un sistema social en el que todo está vinculado por su lógica funcional, y esto por lo tanto implica la idea de equilibrio social.

Cuando Mariátegui dice que en el Perú hay comunismo primitivo, pero que el feudalismo ya domina dentro del comunismo primitivo, está diciendo también que el capitalismo ya domina dentro del feudalismo. Ya no está mirando etapas, aunque él sigue diciendo que hay etapas. Lo que está encontrando es que todos esos modos no solo coexisten, sino que están articulados. Es una voz solitaria; nadie en el mundo está diciendo semejante cosa. Esta es una brusca subversión que pasa de una idea de totalidad a otra por completo diferente. Creo que se puede reconocer esta súbita irrupción de lo que después es la heterogeneidad histórico-estructural, que en consecuencia propone otra idea de totalidad: un espacio de relaciones que articula a elementos o fenómenos que son heterogéneos, no solo por su origen histórico, sino que está más asociado a su lugar en la nueva estructura.

Sin la experiencia de América no hubiera sido posible llegar a esto. Mariátegui es, de algún modo, el portavoz y el testigo de esto. Se dice que Mariátegui era un socialista romántico porque aún pensaba en la comunidad, y la comunidad era una cosa hoy muy distante. No pensaba dentro de esa trayectoria que parte del dualismo. Comunismo primitivo, con feudalismo, con esclavismo, con capitalismo, etcétera: eso es «no pensable», eso «no es posible». ¡Solo a un romántico se le ocurre! Hoy día mucho menos. En la época de Mariátegui —estamos hablando de 1926 - había miles de comunidades reconocidas. Muchas de ellas ya no están, pero, digamos, la idea, la práctica de la comunidad regresa. La reciprocidad regresando por todo el mundo, además.

La propuesta que él hizo de totalidad no solamente es pertinente sino absolutamente necesaria, es inevitable. No hay el modo de dar sentido a nada en el universo y mucho menos en la existencia social y en la trayectoria de la existencia social, sin una idea de totalidad. ¿Por qué? Porque la producción de sentido apunta a la relación entre las gentes, entre nuestra especie y las demás, entre las entidades que 
hay en el universo, vivas o no. Me preguntaron el otro día por qué es que yo coloco la palabra naturaleza al final de la lista de ámbitos de práctica social. Pero la lista no es secuencial. La idea de naturaleza como algo separado tiene que ser revuelta.

Ciertamente hay un organismo. Nosotros somos un organismo. Hay sistemas, pero no sociales. Una computadora es un sistema; si un chip se malogra deja de funcionar. En América, muchas historias de muchos lugares muy distantes y muy distintos concurren al mismo tiempo y espacio. Hay que admitir que se trata de una totalidad y que se porta como totalidad, pero que tiene una condición de heterogeneidad al mismo tiempo histórica y estructural. Esto, que es una propuesta teórica, política, estética, histórica, implica por supuesto, que no es posible con la misma episteme. No es posible la historia con una teoría diferente. No es posible la estética diferente. No es posible. Entonces, estamos hablando de una propuesta de la idea de totalidad cuyo núcleo central es esta heterogeneidad histórico-estructural; si no, no tendría sentido, la experiencia que encontramos no sería explicable. Por tanto, está en desarrollo una teoría global de un patrón global que termina siendo no solamente global en el sentido genérico, sino porque abarca lo humano como especie, y a la totalidad unitaria.

\section{Preguntas del público}

Estoy haciendo mi tesis sobre el tema de conflictos e identidades en la Amazonía. No sé hasta qué punto toda esta conflictividad que hay últimamente, o la mayor visibilidad de los conflictos actuales, ha permitido visibilizar a estas organizaciones. Ellas no son parte de toda esta única heterogeneidad histórica, este horizonte histórico. Mi pregunta es: ¿hasta qué punto los conflictos han permitido completar el mapa de todas estas diferentes sociedades que hay?

Excelente observación. Lo que quisiera decir sobre eso es algo que también está en debate. Hay un nuevo patrón de conflicto en los últimos 30-35 años. Para darles una fecha, desde 1973 en adelante. No es solamente el golpe de Pinochet, sino el comienzo de la imposición de eso que se llama hoy día neoliberalismo, que comienza ahí en Chile y que luego, en asociación con la señora Thatcher y el señor Reagan, se impone mundialmente. Creo que es posible admitir que hemos ingresado en un periodo histórico totalmente nuevo. Estamos ingresando en otro escenario histórico.

Dije que la primera gran mutación de este patrón de poder fue durante el siglo XVIII, lo que me gusta llamar "periodo revolucionario». Revoluciones industriales, burguesas, que culminan todo este proceso de eurocentralismo. Producen a Europa, y producen este horizonte de sentido histórico llamado modernidad, colonialidadmodernidad, y que es la primera gran mutación. Pero ¿por qué mutación? Porque 
ahora tenemos una nueva entidad histórica: Europa Occidental, que es la sede del centro de control de este patrón de poder, y que luego expande su dominio colonial sobre todo el planeta. Mundializa el patrón de poder. Por lo tanto, también lo hace más heterogéneo.

Se han dado muchas crisis, ¿cuál creen ustedes que fue más importante? ¿Qué fue lo más importante para la vida del mundo actual, para la vida de cada uno de sus individuos? Para algunos ya era predecible lo que ocurriría con el llamado campo socialista porque ya estaba ocurriendo, y venía ocurriendo con eso llamado Unión Soviética. Hizo una implosión casi sin ruido. Se terminó. Sin guerras, sin terremotos, sin incendios, sin revoluciones. Simplemente hizo implosión por dentro y terminó. ¿ $\mathrm{O}$ no fue así? ¿Recuerdan quién fue el protagonista de este momento? ¿Quién puso fuera a Gorbachov? ¿Lo recuerdan? Boris Yeltsin. Él tenía un título fantástico, era el secretario general del partido comunista de la federación rusa. Nada menos. Y fue el campeón del más salvaje neoliberalismo, que fue un saqueo diario, una devastación de todo lo que había y lo que no había.

Muy poco tiempo después se publicó en Nueva York un texto realmente notable. No hay tantos textos notables en el mundo: Los peligros de la democracia, y lo firma un tal Popov. Dice, para resumirlo, dos cosas realmente notables. La destrucción de la Unión Soviética ha sido el resultado de una alianza entre nosotros los intelectuales, los profesionales, los técnicos y los trabajadores. Pero no queremos las mismas cosas. Los trabajadores quieren igualdad social; nosotros no: nosotros queremos una meritocracia. Por lo tanto, si por democracia se entiende la expansión de la igualdad social, eso es un peligro. Por eso su libro se llama «los peligros de la democracia». Popov fue el primer alcalde electo de Moscú en toda la historia. Él era, en la víspera, un profesor de filosofía dialéctica en la universidad de Leningrado.

¿Cómo podemos apreciar en algunos discursos del movimiento indígena una episteme que no ha cambiado en realidad? Tienen un discurso esencialista del indigena. Me parece, por momentos, moderno, por ejemplo.

Tienes razón. Pablo Stefanoni tiene un texto, «Los periodos del pachamamismo». Hay una fracción, un sector, una tendencia, no sé exactamente, en el debate de los aymara, que puede calificarse de esencialista, más que fundamentalista. Pretenden ser los únicos originarios, y lo que están reclamando es algo muy notable: la reinstauración del Tahuantinsuyo. El problema es que, claro, esto remite a memorias e historias que no son suficientemente investigadas ni conocidas. Si a ustedes les dicen que los aymara eran formidables navegantes, ustedes dicen ¿qué?, ¿cómo? El Collasuyo era realmente un área de excepcional vigor histórico, cultural, político, que produjo navegación de comercio. Llegaron hasta la Polinesia. Pero no están a favor de la idea de igualdad social para nada. 
Lo mismo en el Brasil, por ejemplo: hay un movimiento Orisha cuya propuesta central no es igualdad social. Sostienen que la jerarquía social no solamente es real, sino necesaria y legítima; de otro modo no se podría organizar una extensa sociedad que tenga sentido. Por eso, les estaba diciendo que la idea de igualdad social no es una idea nueva, pero se produce, desde la sede central del patrón de poder, como un elemento de nuevo sentido común. ¿Quién se animaría a decir en público eso hoy día? Muy pocos. La idea de igualdad social forma parte de un sentido común, es una demanda universal que parte de un sentido utopístico. Porque en ningún lugar del mundo hay igualdad social plena. Y la lucha exacta es por cómo llegar a una sociedad de iguales. La idea, desde Tomas Moro en adelante, es exactamente esa: que en el mundo andino había poblaciones que se organizaban entre iguales, que trabajaban entre iguales, se distribuían como iguales y vivían como iguales. Es decir, la idea romantizada de comunidad andina sin jerarquías.

Hay una inteligencia aymara en Bolivia graduada en importantes universidades del mundo. A ese debate, entonces, hay que mirarlo con mucho ojo. Ticona (intelectual aymara) apunta a la ancestralidad aymara, que es un valor en sí mismo. Es la idea de territorio la que está en este debate; no es solamente la idea del respeto al medio ambiente. Es la misma idea físico-histórico-metafísica, un poco mística, de que hay algo sagrado llamado territorio. Es indispensable admitir que algo emerge en el mundo andino, para comenzar. Pero, después, en el mundo llamado Centro América, y ahora en el África, en la India, en todas partes, todo lo que fue indigenizado (¿qué es lo «indígena»?: lo que no es europeo) ahora vuelve al escenario. Queremos reconocimiento, queremos que nuestra cara esté presente, que lo que nosotros queremos, pensamos, necesitamos, esté presente. Y, parte de este debate viene ahí. Este debate es visibilizado por los conflictos. Es un momento en que va emergiendo y produciéndose un posible horizonte alternativo en el cual la indigeneidad no puede dejar de estar presente. Ya el mero uso del término «indígena» es una concesión a la colonialidad. Por eso, la colonialidad no puede ser confundida ni con poscolonialidad ni con colonialismo; es otra cosa. Hay un patrón de poder y eso es exactamente lo que tiene este origen y carácter colonial.

Si uno viaja por el mundo, uno encuentra que en todo el mundo usan blue-jean ¿no es cierto? En el Perú, si ustedes van por las calles de Lima, pocas mujeres usan falda. Han colonizado el vestido del varón, pero no usan los bolsillos: usan cartera. Es un modo de colonizar. Entonces, hay un patrón de conflicto donde ahora están el género, la sexualidad y sus modalidades, y las relaciones en torno al sexo, sus productos, y sus recursos.

Me parece que su propuesta, que entiendo no es solo suya sino de un conjunto de autores que están trabajando en esta linea, reclama una nueva sociologí. En particular, otras 
categorías de análisis. Las categorías que normalmente tenemos no son suficientes, y entonces mi pregunta iría por ese lado. ¿Por qué usar algunas categorías, por ejemplo, la noción de raza, para entender una realidad como América Latina, que es mucho más compleja? Como hemos visto, esta noción de raza tiene un origen determinado históricamente. Sin embargo, hay muchos autores en el Perú que siguen hablando de esta noción como si tuviera el sentido que tiene, por ejemplo, en Europa o Estados Unidos, y no se desmonta esa categoría. ¿Qué piensa al respecto?

Yo reclamo tratar de pensar desde, con, por medio de la heterogeneidad histórico-estructural. Cada categoría es una cuestión abierta. ¿Qué es una teoría? Una propuesta de cuestiones. Propuesta de cómo y dónde ir a buscar respuestas para contestar esas cuestiones. Una doctrina, al contrario, produce una secuencia de afirmaciones que están, cada una de ellas, apoyada en la otra como verdadera.

Una nueva propuesta teórica permite volver a una idea diferente de totalidad, porque sin la idea de totalidad nada es explicable, nada tendría sentido. No hay nada que tenga sentido si no está en relación con, provenga de, vaya a un campo de relaciones. La totalidad no solo es necesaria si no que es pertinente para toda actividad de conocimiento. Esa totalidad no puede ser sino, para nuestros fines ahora, un campo de relaciones donde se asocian elementos que son histórica y estructuralmente muy heterogéneos. Esta es la condición misma de existencia social. No hay existencia histórica social que no tenga este carácter. Hay que partir de esto.

Entonces, cuando uno dice «raza» está hablando al mismo tiempo de algo que emerge como imagen, como un elemento de subjetividad, pero que muy pronto pasa a ser parte ya no de la subjetividad sino de la materialidad de las relaciones sociales. Tú eres indio, tú eres negro, tú eres esto. La palabra "mestizo» significa que están hibridándose seres de naturalezas que no son las mismas. Mestizo es una hibridación. Por eso las famosas castas coloniales, sobre todo en el siglo XVIII. Yo he llegado a identificar 35 castas en América del Sur, y en el Perú en particular. Y en México es, más o menos, lo mismo. ¿Qué es una casta? Alguien que socialmente, y después legalmente, viene de tales hibridaciones, tiene estos colores, debe vestir de tal o cual modo, vivir en tales áreas. Y, por lo tanto, sus relaciones sociales tienen que ser de cierto tipo y no de otros. Eso es una casta. No es una casta en el sentido hindú del término, sino un producto histórico constante y que va cambiando permanentemente. Pero un mulato puede ser de varios colores. Desde casi blanco hasta casi negro. Por eso, se propuso que la palabra «color» debe ser admitida como el hecho natural, así como el sexo en relación con el género. Porque «color» no existe como algo asociado a la idea de raza —eso es del siglo XVIII — y no viene de América Latina, viene desde América del Norte.

Los llamados indios, en lo que hoy es Estados Unidos, no son parte de la sociedad. Están afuera. Y son naciones. Cuando llegan los peregrinos, y más tarde 
los holandeses, irlandeses, hacen tratados con las «naciones» llamadas indias. Hasta que los ingleses van a conquistar el resto del mundo y cuando regresan a Estados Unidos ya no hay naciones: son «tribus». En el siglo XVIII ya no hay naciones, son tribus. Todas son tribus. Y, como los indios, las tribus indígenas, no son parte de la sociedad colonial, el único sector dominado y explotado son los negros, los africanos.

La palabra «blanco» no existe durante la colonia latinoamericana en ningún momento, en ningún periodo. La palabra blanco es posterior. Viene desde Estados Unidos. El único dominado activo en la sociedad es llamado negro. Por lo tanto, el que lo manda se llama blanco. Y, como blanco es europeo, la palabra europeo y la palabra blanco pasan a ser, más o menos, sinónimos. La castificación de la población es contemporánea en esto. En consecuencia, lo que evoca la palabra «raza» es una heterogeneidad de situaciones.

En las famosas guerras civiles de los encomenderos contra los realistas a mitad del siglo XVI en el virreinato peruano, me hace acordar una casta tan grande como el Tahuantinsuyo. En ese virreinato hay una revuelta de los encomenderos cuando las encomiendas son suprimidas. Entonces, si se suprime la encomienda: ¿quién va a trabajar para nosotros? Se rebelan, piden autonomía. Y como no todos los espańoles los van a apoyar, su tropa está hecha parte de indígenas y esclavos negros. Es interesante porque estamos hablando de la mitad del siglo XVI; por lo tanto, probablemente había no más de una generación nacida acá. Los demás eran gentes procedentes directamente de algún lugar de África. Entonces, una vez libres, cada uno se maneja con su experiencia, su memoria y su talento. Varios de ellos pasan a ser capitanes del ejército insurrecto.

¿Capitán, un negro? No es pensable, porque para ser capitán en el ejército español había que ser noble. Capitán, en el ejército colonial, era necesariamente noble. Por lo menos hidalgo, noble de provincia. Pero no negro. Ahora, un talentoso guerrero de origen africano, tal vez con jerarquía nobiliaria en su lugar de origen, es aceptado. Y, soldados hispanos, o ibéricos, tienen que cumplir las órdenes del capitán negro. Cuando los encomenderos son derrotados, el pacificador llamado La Gasca produce el más draconiano posible de los decretos contra los negros. No se le va a ocurrir a nadie, ni a ellos, a nadie en adelante la idea de que un negro pueda ser o libre, o jefe. Entonces, los castigos son simplemente abominables. Si es sospechado de mentir, le cortan la lengua. Si es sospechado de robar, le cortan la mano. El decreto existe, está en el archivo municipal.

En resumen, la idea de raza es una categoría ella misma heterogénea que, por lo tanto, opera de manera heterogénea de muchos modos, en diferentes medidas, en diferentes intensidades, a varias escalas, de manera muy diferente. Esta perspectiva es indispensable para defenderse de toda intromisión que haga esta tendencia de 
homogenizar o de simplificar, o de convertir una cuestión de una afirmación o una teoría en una doctrina. La idea de la heterogeneidad cultural, por ejemplo, es muy vieja; pero la idea de heterogeneidad histórica es latinoamericana. Es de los años sesesenta. Tiene fecha y texto. Su más próximo antecedente probablemente es Mariátegui.

¿Cómo salir del eurocentrismo? ¿Con qué herramientas, en todo caso, no eurocéntricas se puede salir de la mirada eurocéntrica? ¿En qué circunstancias sociales, políticas, económicas se puede salir de esa mirada?

No ser eurocentrista no quiere decir ser antieuropeo. La idea no es reemplazar el eurocentrismo con algo llamado latinoamericacentrismo, o africacentrismo. No está lo europeo en cuestión. Lo está el eurocentrismo en tanto hay un modo de producir conocimiento fundado en el dualismo radical post-cartesiano, con la negación de la idea de totalidad o su admisión de manera inapropiada, organicista, sistémica, operativista. Está en cuestión este piso epistémico que, sin duda, es demostrable que tiene una asociación racista, sobre todo cuando se formaliza desde el siglo XVII. No se podría ni siquiera pensar lo que hace Yanacocha en Cajamarca, sin admitir que no está solamente el lucro ahí dentro. Pero, además, es obvio que su idea de los demás es despreciativa. Hay un racismo incorporado perceptiblemente en esta destrucción tan abierta y explícita del medio ambiente. Lo que está aquí en cuestión, por lo tanto, es una perspectiva epistémica, teórica, histórica, frente a otra opción alternativa. No hay un latinoamericacentrismo en esto más allá de la ambición histórica, demostrable, de que es este el espacio inicial y el tiempo inaugural de la constitución de este patrón de poder.

No se trata de ser antieuropeo, o algo por el estilo. Hay una propuesta de una perspectiva de conocimiento frente a otra. Como he dicho en otro texto, «Don Quijote y los molinos de viento en América Latina», hace ver como un gigante lo que son molinos de viento. Por lo tanto, no logramos identificar los problemas. El eurocentrismo, ¿hace ver molinos de viento? No. Cubre el molino de viento, le hace ver como un gigante. No podemos identificar nuestros problemas; por lo tanto, no podemos resolver nuestros problemas. Se requiere, por lo tanto, salir de las rejas eurocéntricas de producción de imaginario y sobre todo de conocimiento. Entonces, también enriquecer, o limpiar, el imaginario. Es muy importante esto.

Cuando usted dice la palabra «revolución», en su imaginario usted tiene la toma de la Bastilla, la toma del Palacio de Invierno, etcétera. Pero la idea de que algo pueda ocurrir de manera que subvierta el orden sin este tipo de acontecimientos, y que produzca otra manera de existencia social, es decir, esta producción democrática en una sociedad democrática no puede tener un solo camino en un mundo que es demasiado heterogéneo. El imaginario tiene que ser depurado, corregido y 
enriquecido. Por eso mi insistencia es la de poder entresacar las implicaciones epistémicas y teóricas del Quijote, que no por accidente está pasando de la primera modernidad a la segunda modernidad, ¿̇no es cierto? Está aún la ideología caballeresca. Habita la cabeza cuando la práctica social está en otro mundo. Por eso, la escena del Quijote embistiendo contra un gigante, atacado por un molino de viento, es la gran imagen que da cuenta de ese momento, de ese proceso en que otra cosa está interviniendo.

Entonces, ¿cómo se sale de esto? Ya estamos saliendo del eurocentrismo. Ya el hecho de estar discutiendo aquí, entre nosotros, ya estamos saliendo. Estamos comenzando a salir. Solo que hay que tener el máximo cuidado, por supuesto. Las propuestas alternativas no vienen limpias y libres de todo. Vienen con todo; es decir, con el eurocentrismo. Estamos hablando una lengua eurocéntrica. Un espańol se molesta cada vez que me escucha, por supuesto. Porque en América Latina hablamos, obviamente, un español miles de veces más rico, y poderoso, y expresivo, que cualquiera en Espańa. Este es un mundo mucho más rico históricamente, y hoy estamos finalmente admitiendo la diversidad y la riqueza de este mundo. Por eso, por todo esto, el español latinoamericano no por nada tiene cinco premios Nobel. España tiene tres, y muy mediocres. Bien, hasta aquí llegamos. 